\title{
COMPARISON OF CONVENTIONAL DOUBLE-HELICAL AND CURVILINEAR CYLINDRICAL GEAR DRIVES IN TERMS OF TRANSMISSION ERRORS AND STRESS
}

\begin{abstract}
Summary
Curvilinear cylindrical gear drives are similar to double-helical gear drives as they can avoid the axial thrust during the meshing process. Whether curvilinear cylindrical gear drives are better than double-helical gear drives is a problem to be solved. In this paper, a new geargenerating method for curvilinear gears is proposed based on the theory of gearing. Two different single-side face-milling cutters are used for the generation of concave and convex tooth surfaces, respectively. The curvilinear gear sets being generated have line contact in the meshing process. For the sake of comparison, the double-helical gear sets involved in the comparison study are also a kind of gear sets with line contact. This article includes the following: (1) Comparison of transmission errors and stresses of two types of gear sets with the same contact ratio; (2) Derivation of tooth surface equations, transmission error analysis, and finite element analysis; (3) Four numerical examples which show the advantages and disadvantages of curvilinear cylindrical gear drives.
\end{abstract}

Key words: $\quad$ curvilinear gears, double-helical gears, line contact, transmission error, stress analysis

\section{Introduction}

Curvilinear cylindrical gear drives are a kind of novel parallel-axis gear sets in which the longitudinal tooth shape is a circular arc; their concept has been derived from a Swiss patent in 1914 [1,2]. Their commercial application started in China for the first time in 1980. Since then, the superiority of curvilinear cylindrical gear drives in mechanical performance has been shown in heavy machinery [3]. Since curvilinear gear sets cannot be made into internal gear sets, their potential performance is not entirely explored. Thus, this kind of gear drives is not widely used in the machinery industry [4]. From the perspective of the tooth shape geometry, curvilinear gear drives can avoid axial thrust during high power transmission. Their mechanical performance is similar to that of double-helical gear drives [5].

In terms of contact patterns on gear tooth surfaces, curvilinear cylindrical gear drives are divided into two main groups: curvilinear gears with localized contact, and curvilinear gears 
with line contact. The sensitivity of line contact is higher than that of localized contact due to assembly errors. However, contact stresses of line contact are lower than those of localized contact under ideal assembly conditions [6]. In terms of the pressure angle along the tooth face width, curvilinear gear drives are divided into two main groups: CC-gears and CV-gears [7]. The CC-gear implies that the pressure angle is a constant along the tooth face width. The CCgears are subdivided into five subcategories. The CV-gear implies that the pressure angle is variable along the tooth face width. These gears are subdivided into six subcategories [4].

Generally, face-milling cutters are employed in the generation of curvilinear cylindrical gears. Andrei et al. utilized two different single-side face-milling cutters to generate concave and convex sides of wheel tooth surfaces, respectively [1]. On the other hand, pinion tooth surfaces were generated by the conjugate surfaces of the generated wheel tooth surfaces. The generated curvilinear gear sets belong to CV-gears with line contact [8]. Tseng et al. utilized double-side face-milling cutters to generate gear tooth surfaces; then, mathematical models, transmission errors, and undercutting of gear sets were investigated by the theory of gearing and tooth contact analysis (TCA) $[9,10]$. The generated curvilinear gear sets belong to CVgears with localized contact. This processing method is called the spread-blade face-milling cutter (SBC) method (Fig. 1(a)) [5], where, $r_{o b}$ is the pitch curvature radius of the outside of the blade, $r_{i b}$ is the pitch curvature radius of the inside of the blade, $r_{m}$ is the mean pitch curvature radius of the blade, $P_{m}$ is the width of the tooth space at the middle section, $P_{t}$ is the width of the tooth space at the margin. Chen et al. proposed double-side face-milling cutters with a circular arc profile that is used for the generation of gear tooth surfaces [11-14]. Zheng et al. investigated non-circular cylindrical gear sets with localized contact based on the SBC method [15]. Alfonso et al. employed two different single-side face-milling cutters to generate concave and convex sides of pinion tooth surfaces, respectively, and employed one doubleside face-milling cutter to generate wheel tooth surfaces [5]. The curvature radii of two singleside cutters are determined by the desired contact pattern. The obtained gear sets belong to $\mathrm{CV}$-gears with localized or line contact. This processing method is called the fixed-setting face-milling cutter (FSC) method (Fig. 1(b)); the parameters in the figure are similar in meaning to those in Fig. 1(a). In addition, the hobbing method [16,17], the scanning method by tooth profiles [18-20], and the parallel linkage method [21-23] also are used for the generation of curvilinear gears.

In this paper, a new generating method is proposed based on single-side face-milling cutters. Two different single-side face-milling cutters are used for generating concave and convex sides of pinion tooth surfaces. When processing the concave sides, a single-side face-milling cutter with outer blades is employed; when processing the convex sides, a single-side face-milling cutter with inner blades is employed. The centre of the cutter with inner blades is offset with respect to the other cutter by a specific value (Fig. 1(c)), where, $r_{o b}$ and $r_{i b}$ are the pitch curvature radii of the outer and inner blades, respectively. The terms $r_{m o}$ and $r_{m i}$ are the mean pitch curvature radii of the outer and inner blades, respectively. Similarly, concave and convex sides of the wheel are also generated independently by the same method. The generated gear sets belong to CC-gears with line contact.

Many scholars have sought to reveal the advantages and disadvantages of CC-gears with line contact. In previous studies, curvilinear gears have been compared with spur gears and helical gears [24], but there are no comparative studies for curvilinear gear drives and double-helical gear drives. Here, the double-helical gears have a tool withdrawal groove in the middle transverse section of the gear; they are called traditional double-helical gears. 
Curvilinear Cylindrical Gear Drives in Terms of Transmission Errors and Stress

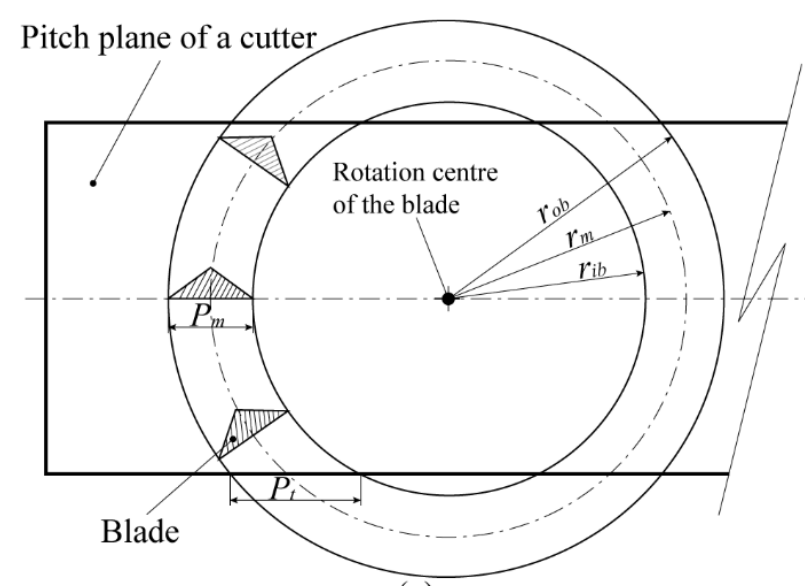

(a)

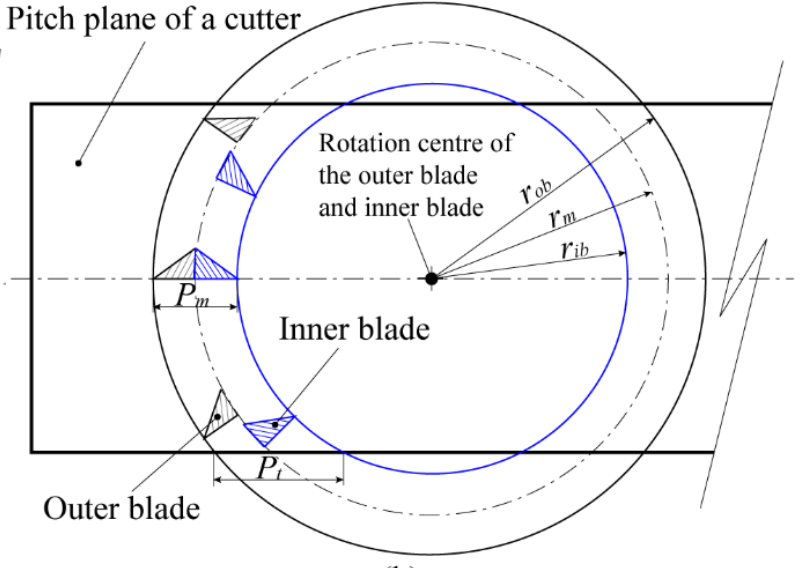

(b)

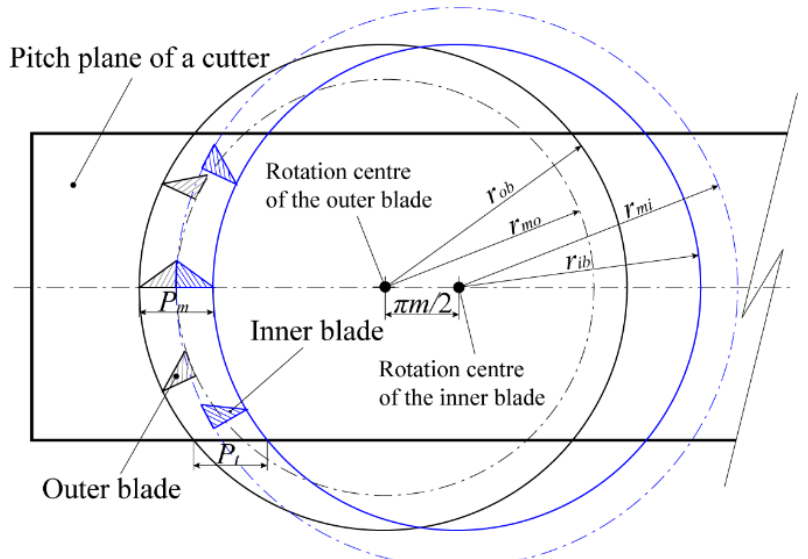

(c)

Fig. 1 Three different generating methods for curvilinear gears: (a) SBC method $\left(P_{m}<P_{t}, r_{o b}-r_{i b}=\pi m / 2\right)$;

(b) FSC method $\left(P_{m} \neq P_{t}, r_{o b}-r_{i b}=\pi m / 2\right)$; (c) The method proposed in this paper $\left(P_{m}=P_{t}, r_{o b}=r_{i b}\right)$

The main research contents of this paper include:

(1) Derivation of tooth surface equations of CC-gear drives with line contact by a new processing method.

(2) Establishment of a mathematical model of transmission errors for CC-gear drives.

(3) Taking the CC-gears as an example, development of a finite element model of gear drives for stress analysis.

(4) Investigation into transmission errors and stresses of two types of gear sets, respectively, in the case when basic design parameters (such as modulus, number of teeth, contact ratio) of the curvilinear gear sets are equal to double-helical gear sets.

\section{Method for generating gear tooth surfaces}

\subsection{Generation of tooth surfaces of conventional double-helical gears}

Regarding the process for the generation of conventional double-helical gears, we assume that it can be carried out by two hypothetical rack-cutters in which helix angles are opposite to each other $(\beta$ and $-\beta)$. One of the rack-cutters is used for generating half of the double-helical gear. The other rack-cutter is used for generating the other half of the doublehelical gear. The process for the generation of conventional double-helical gears is similar to that for helical gears. The process for the generation of helical gears is shown in Fig. 2. The origin $O_{P}$ of the coordinate system $S_{P}\left(x_{p}, y_{p}, z_{p}\right)$ is attached to the centre of rotation of the 
helical gear blank, and its axis $z_{P}$ is perpendicular to the end face of the gear blank. The three axes of the coordinate system $S_{c}\left(x_{c}, y_{c}, z_{c}\right)$ are parallel to the ones of the fixed coordinate system $S_{P}$, and its origin $O_{c}$ is separate from the origin $O_{P}$ by a distance $r_{P}$ along the axis $y_{P}$; where, $r_{p}$ expresses the pitch radius of the gear being generated. The coordinate system $S_{b}\left(x_{b}, y_{b}, z_{b}\right)$ is located on the rack-cutter pitch plane; it rotates $\beta$ around the $y_{c}$ axis, where $\beta$ is the helix angle of the helical gear.

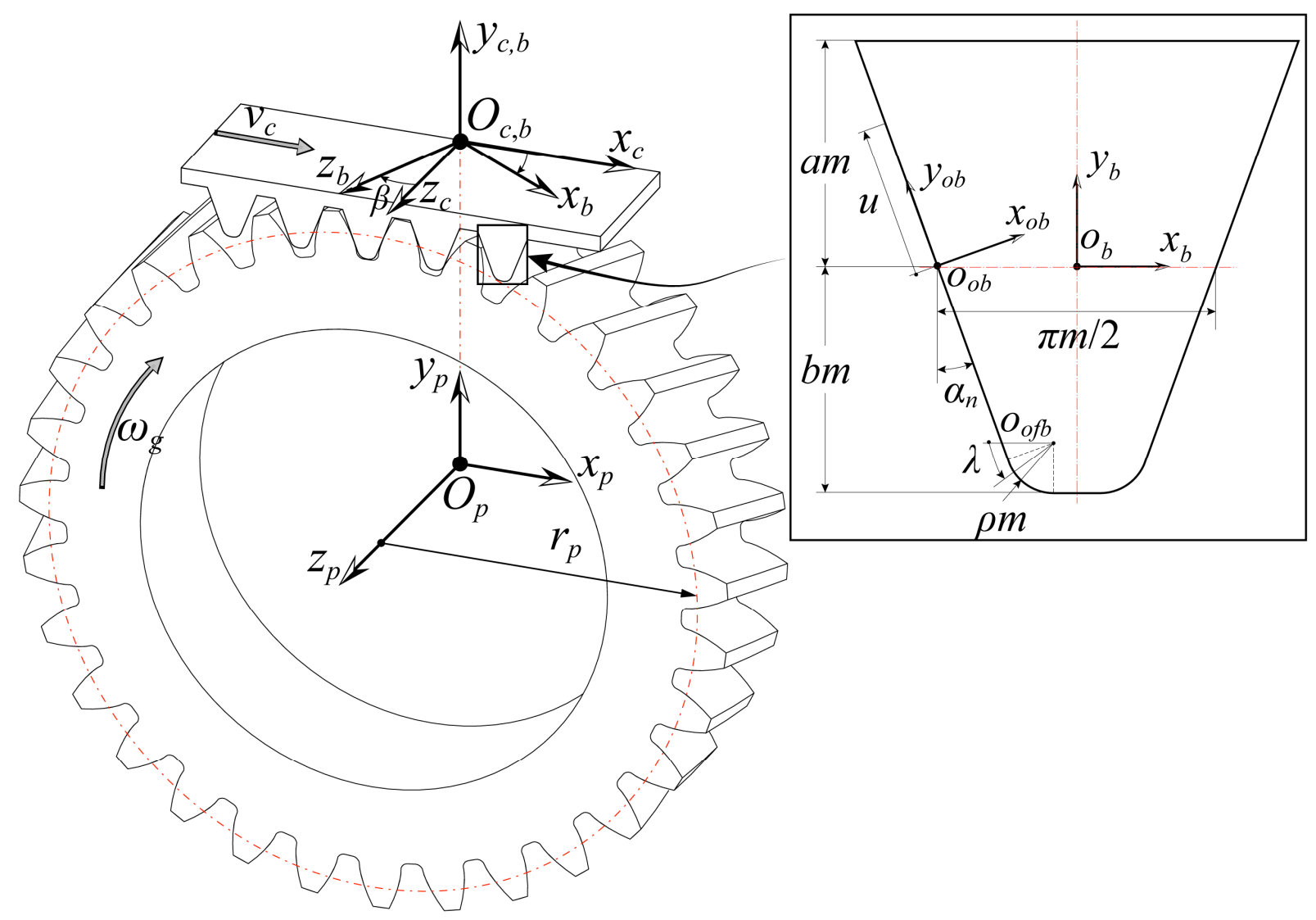

Fig. 2 A mechanism for the generation of helical gears by a rack-cutter

During the generating process, the gear tooth surfaces are generated as the envelope to a family of positions of the rack-cutter tooth surfaces in their rolling motion without sliding relative motion over the gear pitch cylinder. The rack-cutter pitch plane remains tangential to the pitch cylinder of the helical gear. The translational speed of the rack-cutter is $v_{c}$ along the axis $x_{c}$; it is perpendicular to the axis of rotation of the helical gear blank, and the helical gear blank is rotated with angular velocity $\omega_{g}$ around the central axis $z_{p}$. The translational speed $v_{c}$ and angular velocity $\omega_{g}$ are satisfied in the equation $v_{c}=r_{p} \omega_{g}$.

Based on the above principles, the tooth surface equations of half of the double-helical gear can be obtained by a series of coordinate transformations.

$$
\left\{\begin{array}{l}
\mathbf{r}_{p}=\mathbf{M}_{p, c}(\psi) \mathbf{M}_{c, b}(\beta) \mathbf{M}_{b, o b} \mathbf{r}_{o b}^{(p)}(u) \\
f(\beta, u, \psi)=\left(\frac{\partial \mathbf{r}_{p}}{\partial \beta} \times \frac{\partial \mathbf{r}_{p}}{\partial u}\right) \cdot \frac{\partial \mathbf{r}_{p}}{\partial \psi}=0
\end{array}\right.
$$


Where, the symbol $\mathbf{M}_{j, i}$ represents the transformation matrix from the coordinate system $i$ to $j$. The symbol $\mathbf{r}_{o b}^{(p)}(u)$ expresses the position vector of a point on the straight profile. The symbol $\mathbf{r}_{p}$ represents a coordinate vector on the tooth surface. The variable parameters $\psi, \beta$ and $u$ are used for determining the point coordinates on the tooth surface. In Eq. (1), the second equation is the equation of meshing.

The tooth surface equations of the other half of the double-helical gear will be obtained in the same way. For a more detailed derivation method, please see also [6].

\subsection{Generation of tooth surfaces of curvilinear cylindrical gears}

In this paper, curvilinear cylindrical gears (CC-gear drives with line contact) are generated by single-side face-milling cutters. Schematic diagrams of the cross-sections of single-side face-milling cutters are shown in Fig. 3. The outer blade is used for the generation of concave sides of the gear (Fig. 3(a)); the mean radius of the outer blade is expressed as $r_{m o}=r_{o b}-\pi m / 4$. The inner blade is used for the generation of convex sides of the gear (Fig. 3(b)); the mean radius of the inner blade is expressed as $r_{m i}=r_{i b}+\pi m / 4$. The offset distance between the centres of rotation of two cutters is $\pi \mathrm{m} / 2$ along the axis $x_{c}$ (Fig. 3(c)).

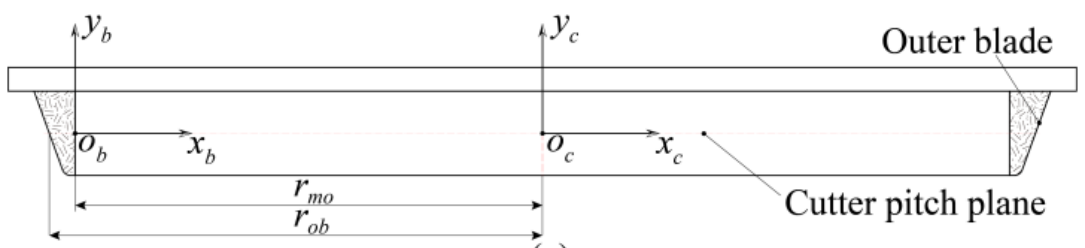

(a)

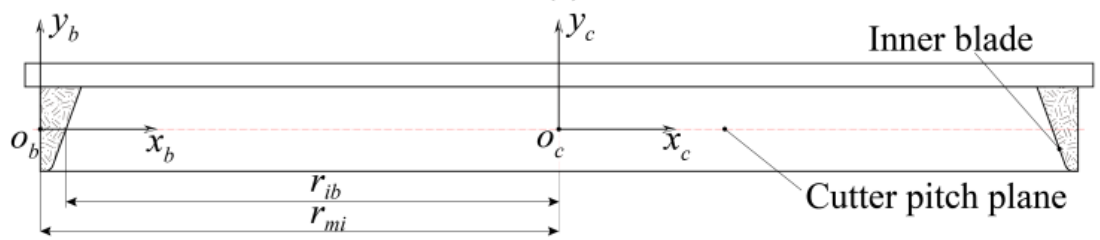

(b)

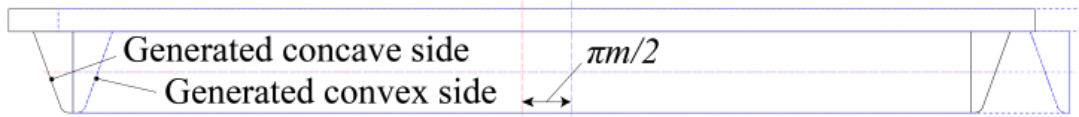

(c)

Fig. 3 A schematic diagram of cross-sections of cutters: (a) outer blade, (b) inner blade,

(c) installation of two cutters

The process for generating the CC-gear with line contact is similar to the FSC method presented in [5]. The distinctive features of these gears are: (1) the pitch curvature radius of the outer blade is equal to that of the inner blade $\left(r_{o b}=r_{i b}\right),(2)$ the rotation centres of two single-side face-milling cutters are separated by $\pi m / 2$, (3) both the pinion and the wheel are generated by two single-side face-milling cutters. 

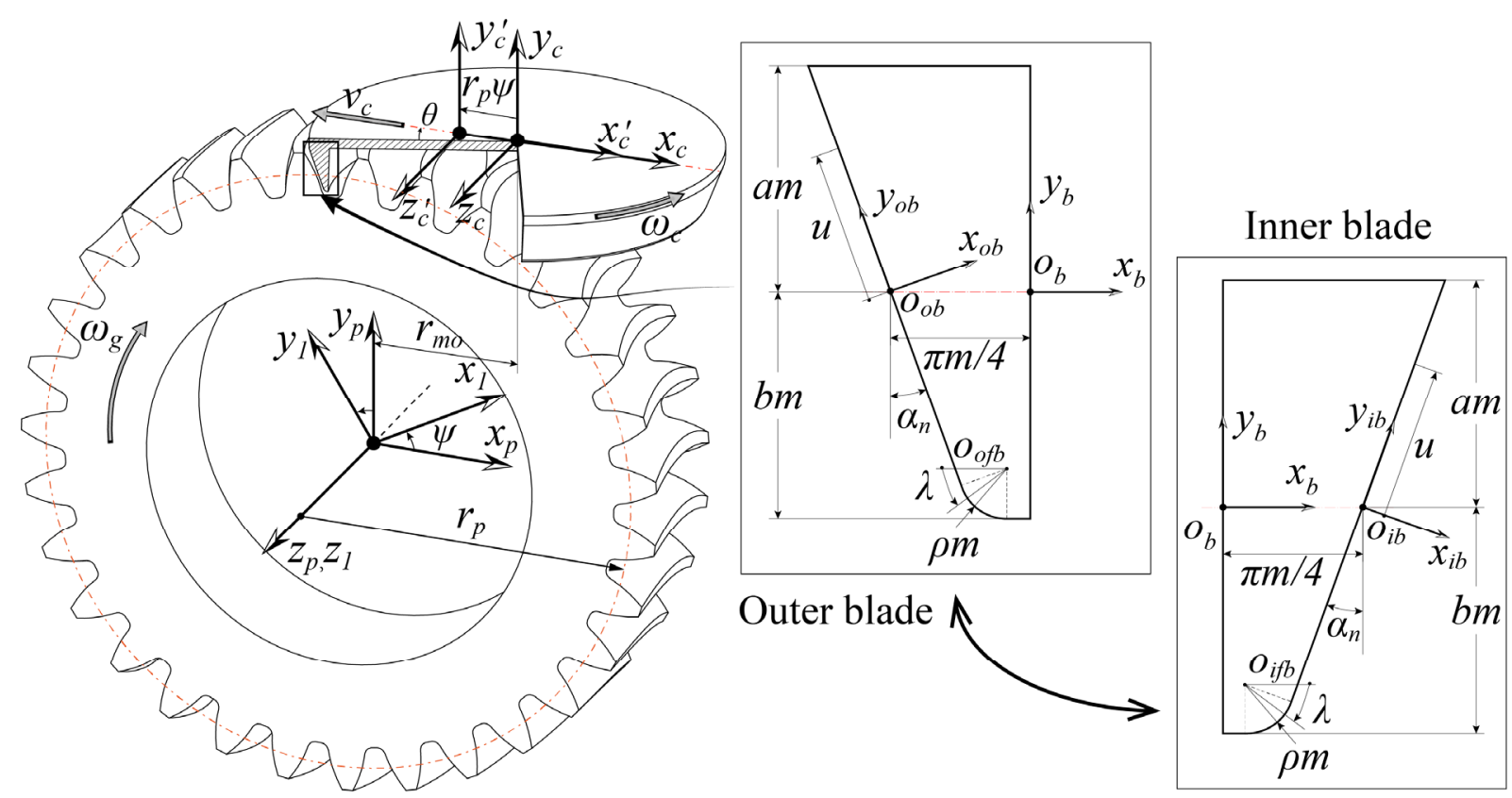

Fig. 4 Curvilinear gear-generating mechanism using a single-side face-milling cutter

Figure 4 shows the curvilinear cylindrical gear generating mechanism, both the outer and the inner blade are enlarged on the right. The coordinate systems $S_{o b}\left(x_{o b}, y_{o b}, z_{o b}\right)$ and $S_{i b}\left(x_{i b}, y_{i b}, z_{i b}\right)$ are fixed to the outer and inner blades, respectively; their respective axes $y_{o b}$ and $y_{i b}$ toward the addendum along with the blade profile and their origins $O_{o b}$ and $O_{i b}$ are located on the pitch plane. The coordinate system $S_{b}\left(x_{b}, y_{b}, z_{b}\right)$ is fixed to the vertical side of the blade, and its origin $O_{b}$ is located on the pitch plane; its axis $y_{b}$ and the origin $O_{b}$ are oriented towards the origins $O_{o b}$ or $O_{i b}$. The distance between the two origins is $\pi \mathrm{m} / 4$. The origins of the coordinate systems $S_{o f f}\left(x_{o f b}, y_{o f b}, z_{o f b}\right)$ and $S_{i f b}\left(x_{i f b}, y_{i f b}, z_{i j b}\right)$ are fixed to the centre point of the edges, and the orientation of each axis is the same as with the coordinate system $S_{b}\left(x_{b}, y_{b}, z_{b}\right)$. The origin $O_{c}$ of the coordinate system $S_{c}\left(x_{c}, y_{c}, z_{c}\right)$ is located on the rotation centre of the cutter, and the plane $x_{c} z_{c}$ coincides with the cutter pitch plane. example.

In this paper, the generation process of the concave side is described in detail as an

The surface of the single-side face-milling cutter can be represented in $S_{c}$ as follows:

$$
\mathbf{r}_{c}^{(p)}(\theta, u)=\mathbf{M}_{c, b}(\theta) \mathbf{M}_{b, o b} \mathbf{r}_{o b}^{(p)}(u)
$$

The symbol $\mathbf{r}_{o b}^{(p)}(u)$ expresses the position vector of a point on the straight profile; it is expressed in the coordinate system $S_{o b}$ as follows:

$$
\mathbf{r}_{o b}^{(p)}(u)=\left[\begin{array}{l}
0 \\
u \\
0 \\
0
\end{array}\right]
$$

The superscript ' $p$ ' expresses the pinion. The subscript ' $o b$ ' expresses the coordinate system $S_{o b}$. The parameter ' $u$ ' expresses the variable parameter. 
The symbol $\mathbf{M}_{b, o b}$ indicates the coordinate transformation from $S_{o b}$ to $S_{b}$; it is expressed as

$$
\mathbf{M}_{b, o b}=\left[\begin{array}{cccc}
\cos \alpha_{n} & \sin \alpha_{n} & 0 & \frac{\pi m}{4} \\
-\sin \alpha_{n} & \cos \alpha_{n} & 0 & 0 \\
0 & 0 & 1 & 0 \\
0 & 0 & 0 & 1
\end{array}\right]
$$

The symbol $\mathbf{M}_{c, b}(\theta)$ indicates the coordinate transformation from $S_{b}$ to $S_{c}$, the parameter ' $\theta$ ' is a variable parameter. This matrix is presented as

$$
\mathbf{M}_{c, b}(\theta)=\left[\begin{array}{cccc}
\cos \theta & 0 & -\sin \theta & -r_{m o} \cos \theta \\
0 & 1 & 0 & 0 \\
\sin \theta & 0 & \cos \theta & -r_{m o} \sin \theta \\
0 & 0 & 0 & 1
\end{array}\right]
$$

The family of the cutter generating surface is expressed in the coordinate system $S_{1}$ as

$$
\mathbf{r}_{1}^{(p)}(\theta, u, \psi)=\mathbf{M}_{1, c}(\psi) \mathbf{r}_{c}^{(p)}(\theta, u)
$$

where

$$
\mathbf{M}_{1, c}(\psi)=\left[\begin{array}{cccc}
\cos \psi & \sin \psi & 0 & r_{p}(\sin \psi-\psi \cos \psi)+r_{m o} \cos \psi \\
-\sin \psi & \cos \psi & 0 & r_{p}(\cos \psi+\psi \sin \psi)-r_{m o} \cos \psi \\
0 & 0 & 1 & 0 \\
0 & 0 & 0 & 1
\end{array}\right]
$$

The parameter $\psi$ in Eq. (7) represents the rotation angle of the gear blank when processing the gear tooth surfaces.

Based on the theory of gearing, the equation of meshing may be determined by the differential geometry approach as follows:

$$
f(\theta, u, \psi)=\left(\frac{\partial \mathbf{r}_{1}^{(p)}}{\partial \theta} \times \frac{\partial \mathbf{r}_{1}^{(p)}}{\partial u}\right) \cdot \frac{\partial \mathbf{r}_{1}^{(p)}}{\partial \psi}=0
$$

Generally, a surface can be expressed by two parameters; however, there are three parameters in Eq. (6). Combining Eq. (6) and Eq. (8) to eliminate one parameter, the concave side of the pinion can be obtained by Eq. (9).

$$
\left\{\begin{array}{l}
\mathbf{r}_{1}^{(p)}(\theta, u, \psi)=\mathbf{M}_{1, c}(\psi) \mathbf{r}_{c}^{(p)}(\theta, u) \\
f(\theta, u, \psi)=0
\end{array}\right.
$$

\section{Computerized simulation of transmission errors}

It is difficult to ensure that there are no assembly errors in the installation of gear sets. However, assembly errors will cause transmission errors during the meshing process, and transmission errors are the key to evaluating the noise and vibration of gear transmission. We 
set up auxiliary coordinate systems for simulating transmission errors under assembly errors, as shown in Fig. 5.

The pinion is fixed to the coordinate system $S_{1}$, and the wheel is fixed to the coordinate system $S_{2}$. The coordinate system $S_{f}$ is rigidly connected to the gearbox frame. Assembly errors $(\Delta V, \Delta H, \Delta A, \Delta C)$ are described by four auxiliary coordinate systems $\left(S_{n}, S_{m}, S_{l}, S_{k}\right)$, where, the symbol $\Delta V$ expresses the intersecting shaft angle error; the symbol $\Delta H$ expresses the crossing shaft angle error; the symbol $\Delta A$ expresses the axial displacement error; the symbol $\Delta C$ expresses the centre distance error. The parameter $C$ denotes the centre distance between the pinion and the gear, $\varphi_{1}$ and $\varphi_{2}$ denote the rotation angle of the pinion and the wheel in the meshing process, respectively. If the rotation angle $\varphi_{1}$ of the pinion is given, then, the real rotation angle $\varphi_{2}$ of the wheel will be solved based on the continuous tangency of two tooth surfaces [6], while, the ideal rotation angle $\varphi_{2}^{\prime}$ of the wheel can be solved by

$$
\varphi_{2}^{\prime}\left(\varphi_{1}\right)=\frac{N_{1}}{N_{2}} \varphi_{1}
$$

Therefore, transmission errors can be defined by

$$
\Delta \varphi_{2}\left(\varphi_{1}\right)=\varphi_{2}\left(\varphi_{1}\right)-\varphi_{2}^{\prime}\left(\varphi_{1}\right)
$$

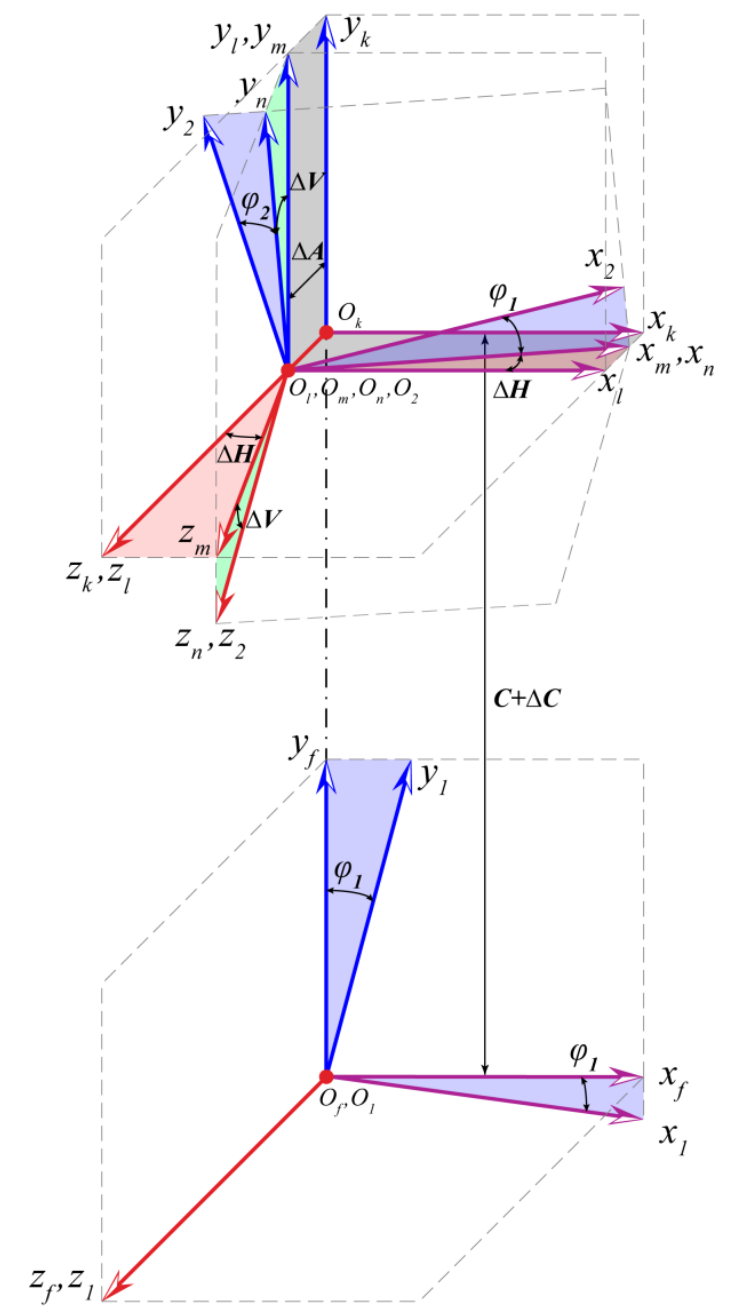

Fig. 5 Coordinate systems for the simulation of transmission errors 
For gear drives with line contact, assembly errors will cause edge contact on the end face of gear tooth surfaces. Namely, the edge of the pinion (wheel) tooth surface is in mesh with the wheel (pinion) tooth surface. The edge contact may be expressed by the following equations [6]:

$$
\left\{\begin{array}{l}
\mathbf{r}_{f}^{(p)}\left(u_{1}, \theta_{1}, \varphi_{1}\right)=\mathbf{r}_{f}^{(g)}\left(u_{2}, \theta_{2}, \varphi_{2}\right) \\
\frac{\partial \mathbf{r}_{f}^{(g)}}{\partial u_{2}} \cdot \mathbf{N}_{f}^{(p)}=0 \\
z_{2}^{(g)}\left(u_{2}, \theta_{2}, \psi_{2}\left(u_{2}, \theta_{2}\right)\right)=\frac{W}{2}
\end{array}\right.
$$

Here, $\mathbf{r}_{f}^{(p)}\left(u_{1}, \theta_{1}, \varphi_{1}\right)$ and $\mathbf{r}_{f}^{(g)}\left(u_{2}, \theta_{2}, \varphi_{2}\right)$ represent the active tooth surfaces of the pinion and the wheel in the coordinate system $S_{f}$, respectively.

$$
\mathbf{r}_{f}^{(p)}\left(u_{1}, \theta_{1}, \varphi_{1}\right)=\mathbf{M}_{f, 1}\left(\varphi_{1}\right) \mathbf{r}_{1}^{(p)}\left(u_{1}, \theta_{1}, \psi_{1}\left(u_{1}, \theta_{1}\right)\right)
$$

Where,

$$
\begin{aligned}
& \mathbf{M}_{f, 1}\left(\varphi_{1}\right)=\left[\begin{array}{cccc}
\cos \varphi_{1} & \sin \varphi_{1} & 0 & 0 \\
-\sin \varphi_{1} & \cos \varphi_{1} & 0 & 0 \\
0 & 0 & 1 & 0 \\
0 & 0 & 0 & 1
\end{array}\right] \\
& \mathbf{r}_{f}^{(g)}\left(u_{2}, \theta_{2}, \varphi_{2}\right)=\mathbf{M}_{f, k} \mathbf{M}_{k, l} \mathbf{M}_{l, m} \mathbf{M}_{m, n} \mathbf{M}_{n, 2}\left(\varphi_{2}\right) \mathbf{r}_{1}^{(g)}\left(u_{2}, \theta_{2}, \psi_{2}\left(u_{2}, \theta_{2}\right)\right)
\end{aligned}
$$

Where,

$$
\begin{aligned}
\mathbf{M}_{f, k} & =\left[\begin{array}{cccc}
1 & 0 & 0 & 0 \\
0 & 1 & 0 & C+\Delta C \\
0 & 0 & 1 & 0 \\
0 & 0 & 0 & 1
\end{array}\right] \\
\mathbf{M}_{k, l} & =\left[\begin{array}{cccc}
1 & 0 & 0 & 0 \\
0 & 1 & 0 & 0 \\
0 & 0 & 1 & \Delta A \\
0 & 0 & 0 & 1
\end{array}\right] \\
\mathbf{M}_{l, m} & =\left[\begin{array}{cccc}
\cos (\Delta H) & 0 & \sin (\Delta H) & 0 \\
-\sin (\Delta H) & 0 & \cos (\Delta H) & 0 \\
0 & 0 & 0 & 1
\end{array}\right] \\
\mathbf{M}_{m, n} & =\left[\begin{array}{cccc}
1 & 0 & 0 & 0 \\
0 & \cos (\Delta V) & -\sin (\Delta V) & 0 \\
0 & \sin (\Delta V) & \cos (\Delta V) & 0 \\
0 & 0 & 0 & 1
\end{array}\right] \\
\mathbf{M}_{n, 2}= & {\left[\begin{array}{cccc}
\cos \varphi_{2} & -\sin \varphi_{2} & 0 & 0 \\
\sin \varphi_{2} & \cos \varphi_{2} & 0 & 0 \\
0 & 0 & 1 & 0 \\
0 & 0 & 0 & 1
\end{array}\right] }
\end{aligned}
$$


In Eq. (12), $\partial \mathbf{r}_{f}^{(g)} / \partial u_{2}$ is the tangent vector of the edge on the wheel tooth surface. The symbol $\mathbf{N}_{f}^{p}$ is the normal vector of the pinion tooth surface. The equation $\frac{\partial \mathbf{r}_{f}^{(g)}}{\partial u_{2}} \cdot \mathbf{N}_{f}^{(p)}=0$ indicates the edge of the wheel tooth surface which is tangential to the pinion tooth surface.

Here,

$$
\mathbf{N}_{f}^{(p)}=\mathbf{L}_{f, 1}\left(\varphi_{1}\right) \mathbf{L}_{1, c}\left(\psi_{1}\right) \mathbf{N}_{c}^{(p)}
$$

Where, the matrix $\mathbf{L}_{f, 1}\left(\varphi_{1}\right)$ is defined as the first-three order submatrix of the matrix $\mathbf{M}_{f, 1}\left(\varphi_{1}\right)$; the matrix $\mathbf{L}_{1, c}\left(\psi_{1}\right)$ is defined as the first-three order submatrix of the matrix $\mathbf{M}_{1, c}\left(\psi_{1}\right)$.

$$
\mathbf{N}_{c}^{(p)}=\frac{\partial \mathbf{r}_{c}^{(p)}}{\partial \theta_{1}} \times \frac{\partial \mathbf{r}_{c}^{(p)}}{\partial u_{1}}
$$

The equation $z_{2}^{(g)}\left(u_{2}, \theta_{2}, \psi_{2}\left(u_{2}, \theta_{2}\right)\right)=W / 2$ expresses that the component of the Z-axis of the vector $\mathbf{r}_{2}^{(g)}\left(u_{2}, \theta_{2}, \psi_{2}\left(u_{2}, \theta_{2}\right)\right)$ is equal to the Z-coordinate of the edge on the gear tooth surface.

In Eq. (12), there are six unknown parameters and five independent nonlinear equations. When the rotation angle $\varphi_{1}$ is given, the other five parameters will be solved by the Newton iteration method. The obtained parameter $\varphi_{2}$ is substituted into Eq. (11), and then, a transmission error will be obtained when the rotation angle of the pinion is $\varphi_{1}$. The rotation angle $\varphi_{1}$ is given from the beginning to the end along the cycle of meshing; it ranges from $-\pi / N_{1}$ to $\pi / N_{1}$; the symbol $N_{1}$ indicates the number of teeth of the pinion. When $\varphi_{1}= \pm \pi / N_{1}$, the maximum transmission error in one cycle of meshing will be solved.

\section{Methodology of stress analysis}

In this paper, the stress analysis mainly includes two aspects: the contact stress and the bending stress analysis. Many scholars have investigated the mechanical behaviour of gear drives for various geometric parameters and assembly errors. In general, many different finite element models of gears are established. The development of traditional finite element models is based on three-dimensional solid models of gears; this is more time-consuming and results in lower precision. Here, we try to avoid these disadvantages. The finite element model based on the ABAQUS ${ }^{\circledR}$ solver is automatically generated by the obtained equations of tooth surfaces. The development process of the finite element model is shown in Fig. 6.

Step 1: Generating point-clouds based on equations of gear tooth surfaces.

Step 2: According to the number of desired elements in the longitudinal and profile directions, point coordinates are filled in the concave side, convex side, and inner ring.

Step 3: At each layer, four adjacent nodes constitute a quadrilateral element.

Step 4: Constructing hexahedral elements with quadrilateral elements on two adjacent layers.

Step 5: Defining contact surfaces on gear tooth surfaces, and point-set on the two sides and the gear rim.

Step 6: Two point-sets are rigidly tied to two reference nodes. Two reference nodes are located on the axis of rotation of the pinion and the wheel, respectively. All degrees of freedom of the reference node 'RP-2' are fixed to zero, and the 
reference node 'RP-1' only retains the rotational movement around the rotation axis. Meanwhile, the torque is applied directly to the reference node'RP-1'. When the stress analysis is accomplished at a certain contact position, then, adjusting the rotation angle of the pinion and wheel, continue to analyse the stress of the gear set until the stresses of all contact positions are analysed in two cycles of meshing.

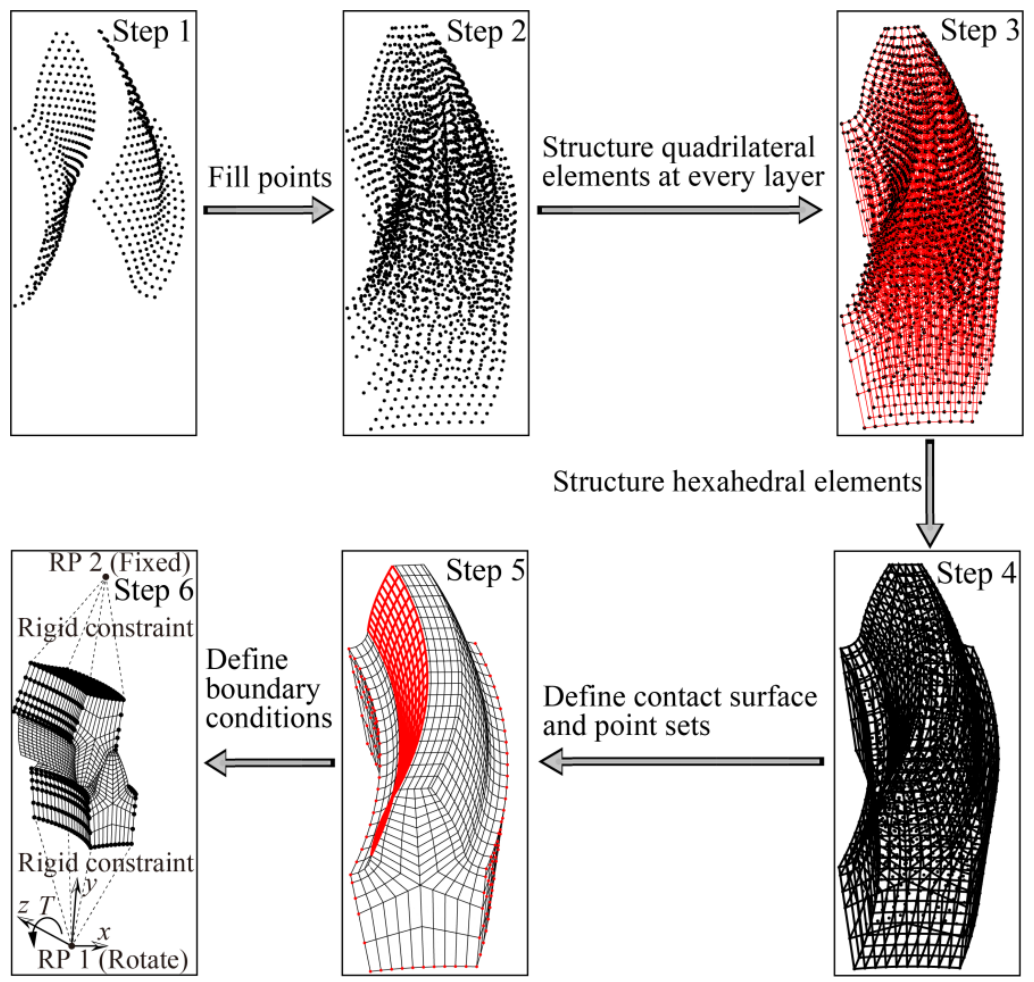

Fig. 6 The development of the finite element model of curvilinear gear drives

To keep boundary conditions far enough from tooth loaded areas, five-tooth models are applied for the stress analysis of gear sets. Figure 7 shows the five-tooth model of two gear sets. In this paper, the number of elements of each five-tooth models is 128030 with 154260 nodes.

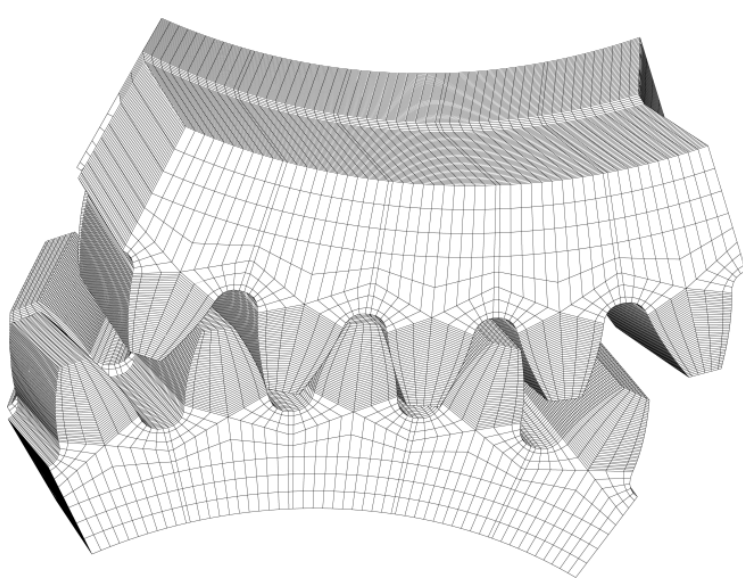

(a)

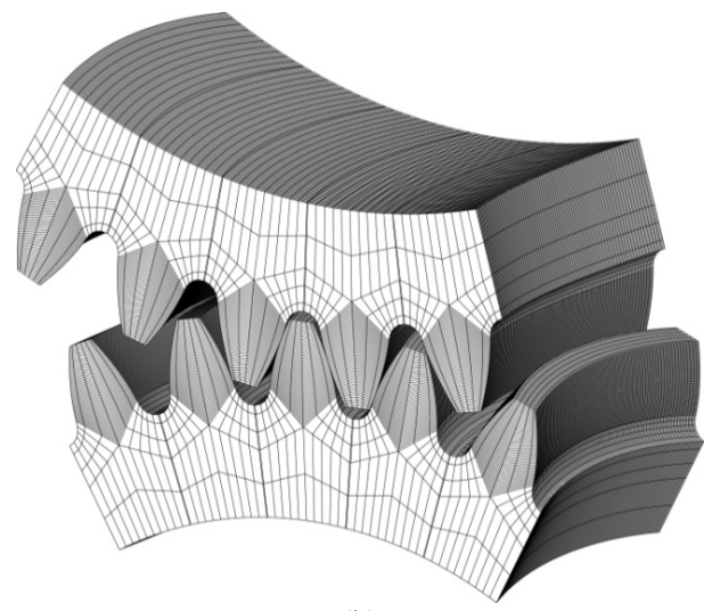

(b)

Fig. 7 Contacting model of five pairs of teeth derived from stress analysis:

(a) conventional double-helical pinion and (b) curvilinear pinion 


\section{Numerical examples}

\subsection{Definition of examples of design}

For double-helical gear drives, the helix angle is used for the representation of tooth shape in longitudinal direction; however, for curvilinear cylindrical gear drives, the mean cutter radius is used for the representation of tooth shape in longitudinal direction. Other common basic parameters of two types of gear drives are exactly the same, as shown in Table 1.

Table 1 Common basic design data of the two types of gear drives

\begin{tabular}{cc}
\hline Parameter & Values \\
\hline Number of teeth, $N$ & $31 / 40$ \\
Module, $m / \mathrm{mm}$ & 4 \\
Pressure angle, $\alpha_{n} / \mathrm{deg}$ & 20 \\
Addendum coefficient, $a$ & 1 \\
Dedendum coefficient, $b$ & 1.25 \\
Face width, $W / \mathrm{mm}$ & 30 \\
Edge radius, $\rho / \mathrm{mm}$ & 0.38 \\
Young's Modulus, $E / \mathrm{MPa}$ & 210000 \\
Poisson's ratio, $v$ & 0.3 \\
Torque, $T / \mathrm{Nm}$ & $400 /-$ \\
\hline
\end{tabular}

Both the helix angle and the mean cutter radius only affect the contact ratios of two types of gear sets. To facilitate a comparative study of two types of gear sets, all geometric parameters of the two gear sets have to be uniform. Hence, the contact ratio is introduced to replace the helix angle and the mean cutter radius.

Contact ratio is an essential criterion of load distribution between the teeth that are in mesh. Its computational method is defined as [6]:

$$
m_{c}=m_{c}^{(c)}+m_{c}^{(l)}(\text { Subscript } \mathrm{c}=\mathrm{dh}, \mathrm{cc})
$$

Where, the superscript "dh" indicates the double-helical gear, "cc" indicates the curvilinear cylindrical gear. The contact ratio $m_{c}^{(c)}$ of the double-helical and the curvilinear gears is determined in a manner similar to that for the contact ratio of spur gears; it is expressed as

$$
m_{c}^{(c)}=\frac{N_{1}\left(\tan \alpha_{a 1}-\tan \alpha_{t}\right)+N_{2}\left(\tan \alpha_{a 2}-\tan \alpha_{t}\right)}{2 \pi}
$$

Where, $N_{1}$ and $N_{2}$ indicate the number of teeth of the pinion and the wheel, respectively. The symbol $\alpha_{t}$ indicates the tangential pressure angle. The symbols $\alpha_{a 1}$ and $\alpha_{a 2}$ are determined by

$$
\cos \alpha_{a i}=\frac{r_{b i}}{r_{a i}}(i=1,2)
$$

where $r_{a i}$ expresses the tip radius of the gear, and $r_{b i}$ expresses the base radius of the gear.

Figure 8 shows the development of the pitch cylinder on a plane. 
Transmission Errors and Stress

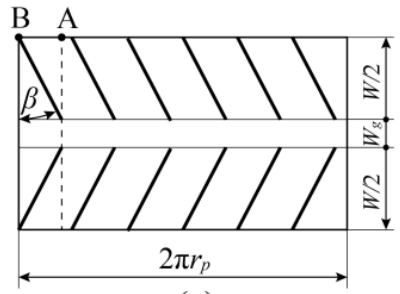

(a)

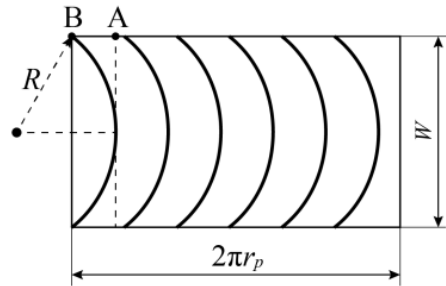

(b)

Fig. 8 The derivation of contact ratio for: (a) double-helical gear with tool withdrawal groove $\left(W_{c}=5 \mathrm{~mm}\right)$, (b) curvilinear gear

In Fig. 8(a), the contact ratio $m_{\mathrm{dh}}^{(l)}$ of the double-helical gear is given by

$$
m_{\mathrm{dh}}^{(l)}=\frac{\overparen{A B} P_{t}}{\pi}=\frac{W P_{t} \tan \beta}{2 \pi}=\frac{W P_{n} \sin \beta}{2 \pi}=\frac{W \sin \beta}{2 a m \pi}
$$

In Fig. $8(\mathrm{~b})$, the contact ratio $m_{\mathrm{cc}}^{(l)}$ of the curvilinear gear is given by

$$
m_{\mathrm{cc}}^{(l)}=\frac{\overparen{A B}}{a m \pi}=\frac{R-\sqrt{R^{2}-\left(\frac{W}{2}\right)^{2}}}{a m \pi}
$$

When the contact ratio $m_{\mathrm{dh}}^{(l)}$ of the double-helical gear is equal to the contact ratio $m_{\mathrm{cc}}^{(l)}$ of the curvilinear gear, then the helix angle and the mean cutter radius can be related by the following equation:

$$
\frac{W \sin \beta}{2}=R-\sqrt{R^{2}-\left(\frac{W}{2}\right)^{2}}
$$

If the mean cutter radius $R$ of the curvilinear gear is given, then the corresponding helix angle $\beta$ of the double-helical gear will be determined by Eq. (28). The mean cutter radius and the corresponding helix angle for four examples of design are shown in Table 2.

Table 2 Examples of design of the two types of gear drives

\begin{tabular}{cccc}
\hline Example, $i$ & Helix angle, $\beta_{i} / \mathrm{deg}$ & Radius of cutter, $R_{i} / \mathrm{mm}$ & Contact ratio, $m_{c i}$ \\
\hline 1 & 15.2853 & 40 & 1.9194 \\
2 & 8.5563 & 60 & 1.8388 \\
3 & 6.0565 & 80 & 1.8000 \\
4 & 4.7046 & 100 & 1.7772 \\
\hline
\end{tabular}

\subsection{Comparison of double-helical and curvilinear gear drives in terms of transmission errors}

Under different assembly errors, based on the theory in Section 3, transmission errors can be obtained for each example of design. The transmission errors of the mentioned two types of gear drives are piece-wise linear functions for each cycle of meshing. To make it easier to compare the studies, maximum transmission errors of the two types of gear drives are employed.

Figure 9 (a) shows the evolution of the peak-to-peak value of the transmission errors for four examples of design under the intersecting shaft angle errors. It is observed that the peakto-peak value of the transmission errors increases with the intersecting shaft angle errors, while the peak-to-peak value of the transmission errors increases with the helix angle of the double-helical gear. Nevertheless, the transmission errors decrease with increasing the disk radius. The evolution of the transmission errors under the crossing shaft angle errors is shown in Fig. 9 (b), and the obtained results are similar to Fig. 9 (a). 
Figure 9 (c) shows the evolution of the peak-to-peak value of the transmission errors for four examples of design under the axial displacement errors. It is observed that the peak-topeak value of the transmission errors increases with the axial displacement errors for the curvilinear gear drives, while the peak-to-peak value of the transmission errors is always almost zero for the double-helical gear. Nevertheless, the transmission errors decrease with increasing the disk radius. The evolution of the transmission errors under the centre distance errors is shown in Fig. 9 (d), and the obtained results are similar to Fig. 9 (c).

In Fig. 9, the symbol $m_{c i}$ in every legend denotes the peak-to-peak deviation of the transmission errors of gear drives under the contact ratio $m_{c i}$. It is observed that the peak-topeak deviation of the transmission errors of gear drives will decrease with a decrease in the contact ratio value, while the peak-to-peak deviation value of the transmission errors will increase with the assembly errors.

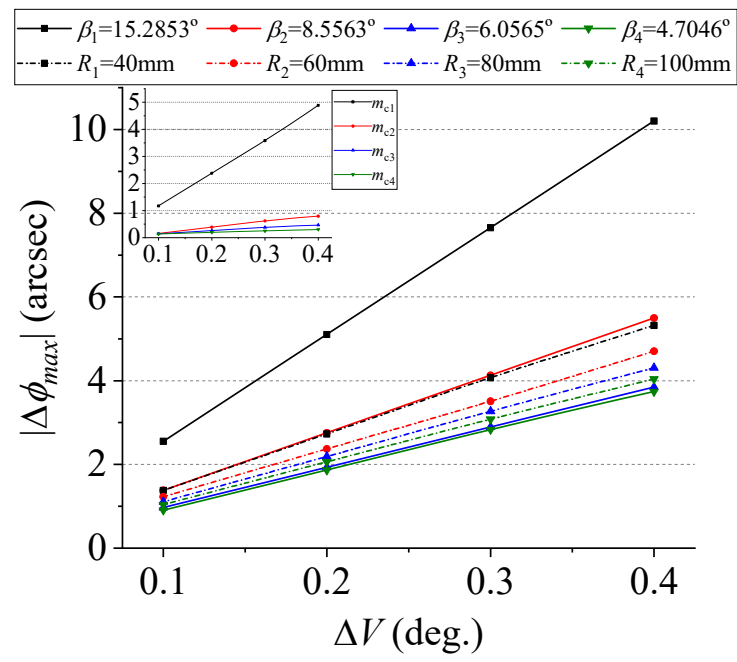

(a)

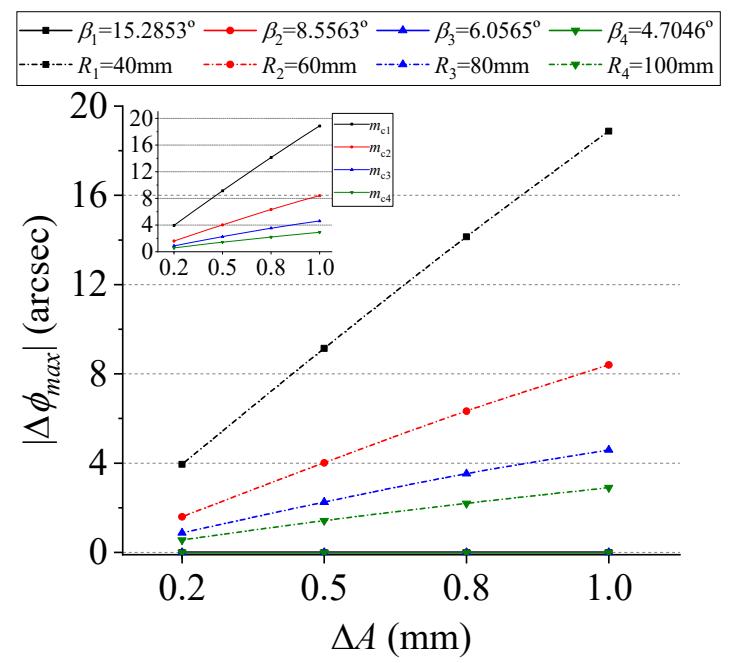

(c)

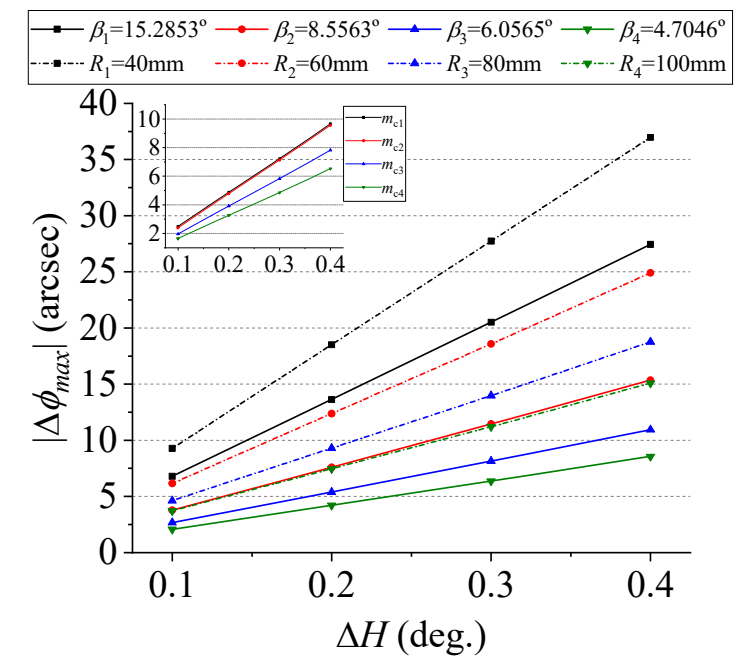

(b)

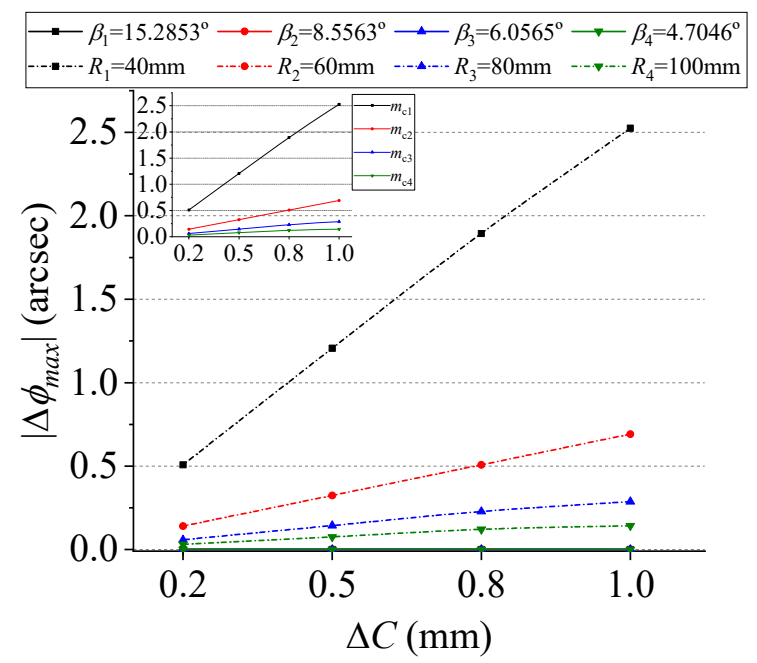

(d)

Fig. 9 Evolution of peak-to-peak value of transmission errors for different misalignment conditions.

\subsection{Comparison of double-helical and curvilinear gear drives in terms of stresses}

Based on the theory in Section 4, the evolution of the maximum equivalent Von Mises contact and bending stresses has been obtained under ideal assembly conditions.

Figure 10(a) shows the evolution of contact stresses for two types of gear drives. The double-helical and curvilinear gear drives show similar tendencies. Since the edge contact 
occurs at the tooth tip, contact stresses greatly increase in contact positions 7-11 and 17-21. In Fig. 12, the edge contact is shown at the contact position 10 as an example for the design 1. The maximum equivalent Von Mises contact stresses will be decreased with an increase in the disk radius at the area of edge contact. However, the maximum equivalent Von Mises contact stresses increase with an increase in the helix angle.

Figure 10(b) shows the evolution of bending stresses for two types of gear drives. It is observed that the helix angle and the disk radius have almost no effect on the evolution of the maximum bending stresses.

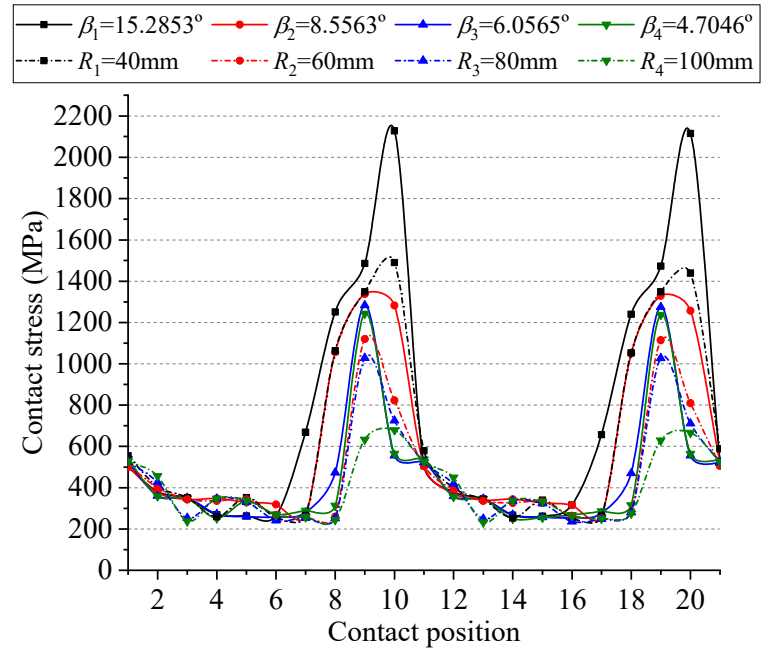

(a)

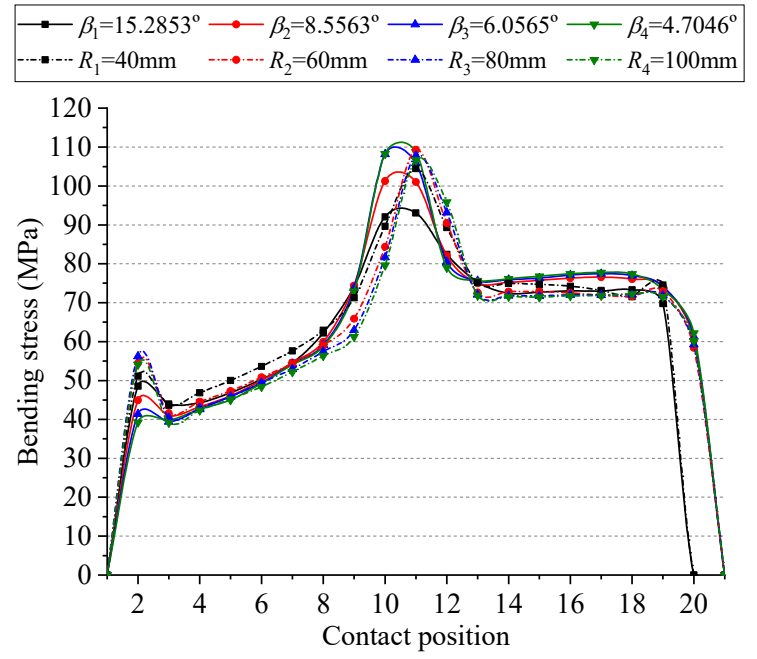

(b)

Fig. 10 Evolution of (a) contact stresses and (b) bending stresses under ideal assembly conditions

According to the evolution of the maximum equivalent Von Mises contact and bending stresses in Fig. 10, the deviation values of the contact and bending stresses are obtained, as shown in Fig.11. The contact ratios have almost no effect on the evolution of the deviation value of contact and bending stresses. When the contact ratio of two types of gear drives is equal, the maximum equivalent Von Mises contact stresses of the two types of gear drives are not equal, especially in the edge contact area where their stress deviation is larger. Bending stresses of the two types of gear drives also show similar tendencies.

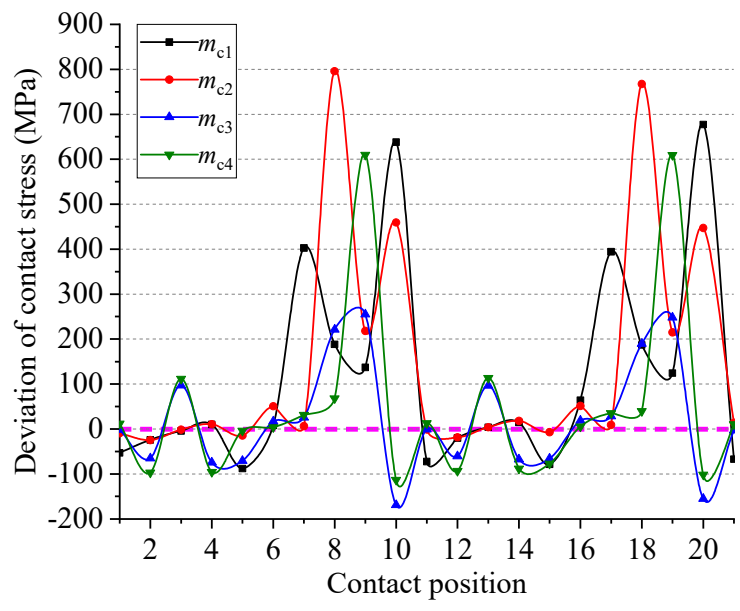

(a)

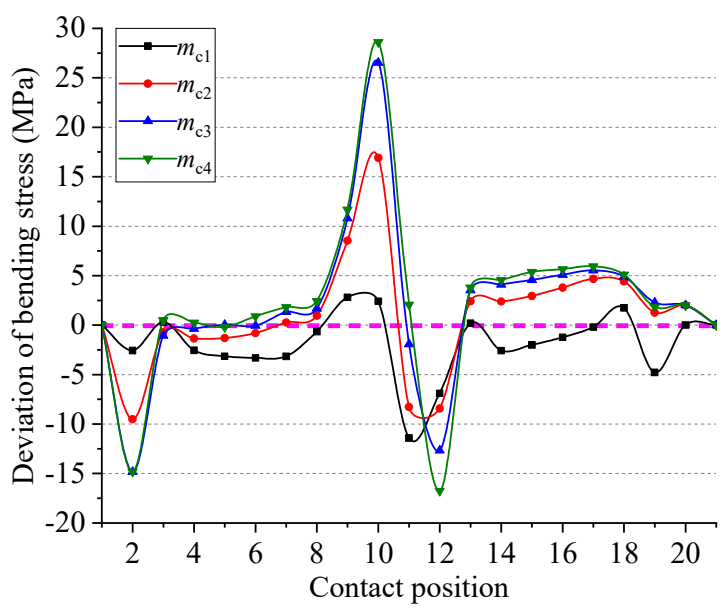

(b)

Fig. 11 Evolution of deviation value of (a) contact stresses and (b) bending stresses under ideal assembly conditions 


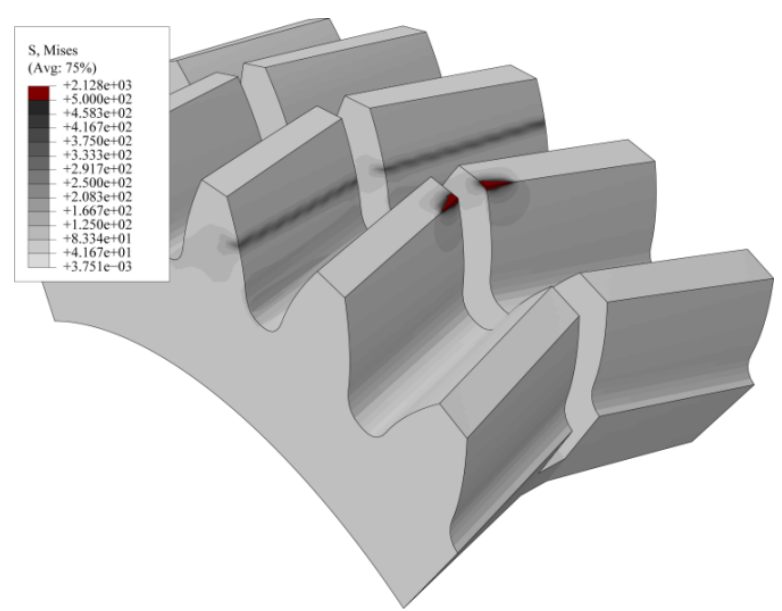

(a)

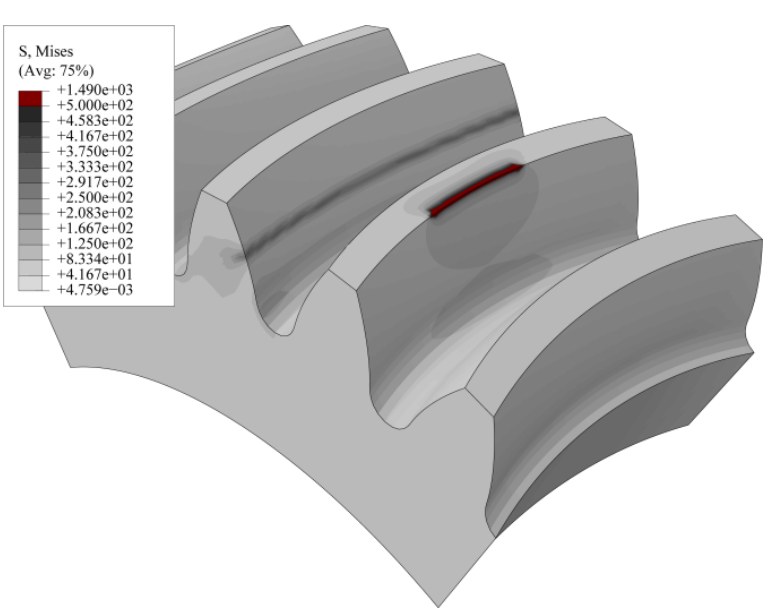

(b)

Fig. 12 Contact stresses at the contact position 10: (a) conventional double-helical pinion and (b) curvilinear pinion

\section{Conclusions}

Based on the above research, the following conclusions can be drawn:

1) When the single-side face-milling cutter is used in the generation of gears, the inner blades are used for the generation of convex sides of the gear and the outer blades for the generation of concave ones. The same method is employed for the generation of the mating gear. The generated gear sets are entirely in line contact in the meshing process.

2) When the contact ratios of the double-helical and curvilinear gear drives are equal, transmissions errors of the two types of gear drives are not equal. The deviation value of transmission errors of the two types of gear drives increases with the assembly errors and the contact ratio.

3) When the contact ratios of the double-helical and curvilinear gear drives are equal, the contact stresses of the two types of gear drives are not equal, and the bending stresses of the two types of gear drives are also not equal. From the mechanical behaviour point of view, no remarkable advantage has been found for the curvilinear cylindrical gear drives.

4) Under the effect of axial displacement errors and centre distance errors, the peak-topeak value of transmission errors is always almost zero for the helical-double gear drives. Therefore, the helical-double gear drives are better than the curvilinear cylindrical gear drives.

\section{Acknowledgment}

The authors express their deep gratitude for the financial support of the Ph.D. Foundation project of Panzhihua University (BKQJ2019077); Key Scientific Research Project of Panzhihua University (2020ZD008); Science \& Technology Plan Project of Panzhihua City (2021ZD-G-1).

\section{REFERENCES}

[1] Andrei, G.; Andrei, L.; Epureanu, A., et al. Numerical simulation and generation of curved face width gears, International Journal of Machine Tools and Manufacture 2002, 42, 1-6. https://doi.org/10.1016/S0890-6955(01)00101-8.

[2] Arafa, H.A. C-Gears: Geometry and Machining, Proceedings of the Institution of Mechanical Engineers, Part C: Journal of Mechanical Engineering Science 2005, 219, 709-726. https://doi.org/10.1243/095440605X31481. 
Curvilinear Cylindrical Gear Drives in Terms of

Transmission Errors and Stress

[3] Liu, S. Curvilinear Cylindrical Gears, Gear Technology 1988, 5, 8-12.

[4] Arafa, H.A.; Bedewy, M. Manufacturability and Viability of Different C-Gear Types: A Comparative Study, Proceedings of the ASME 2012 International Design Engineering Technical Conferences \& Computers and Information in Engineering Conference, Chicago, USA, 12-15 August 2012, paper no. DETC2012-71030, pp. 1-11. https://doi.org/10.1115/detc2012-71030

[5] Fuentes-Aznar, A.; Ruiz-Orzaez, R.; Gonzalez-Perez, I. Computerized design, simulation of meshing, and finite element analysis of two types of geometry of curvilinear cylindrical gears, Computer Methods in Applied Mechanics and Engineering 2014, 272, 321-339. https://doi.org/10.1016/j.cma.2013.12.017.

[6] Litvin, F.L.; Fuentes, A. Gear Geometry and Applied Theory, 2th ed, New York: Cambridge University Press, 2004, p.800.

[7] Arafa, H.A.; Bedewy, M. C-gears in rotorcraft transmissions a novel design paradigm, International Powered Lift Conference, Philadelphia, USA, 5-7 October 2010, pp. 93-100.

[8] Parsons, B.N.; Walton, D.; Andrei, L., et al. Non-Standard Cylindrical Gears. Gear Technology 2004, 21, 30-37.

[9] Tseng, R.; Tsay, C. Mathematical model and undercutting of cylindrical gears with curvilinear shaped teeth, Mechanism and Machine Theory 2001, 36, 1189-1202. https://doi.org/10.1016/S0094114X(01)00049-0.

[10] Tseng, R.; Tsay, C. Contact characteristics of cylindrical gears with curvilinear shaped teeth, Mechanism and Machine Theory 2004, 39, 905-919. https://doi.org/10.1016/j.mechmachtheory.2004.04.006.

[11] Chen, Y.; Gu, M. Tooth Contact Analysis of a Curvilinear Gear Set with Modified Pinion Tooth Geometry, Proceedings of the Institution of Mechanical Engineers, Part C: Journal of Mechanical Engineering Science 2011, 225, 975-986. https://doi.org/10.1243/09544062JMES2441.

[12] Chen, Y.; Li, Z.; Lo, C., et al. A Study on the Improvement of Meshing Characteristics of a Complementary Curvilinear Gear Set Generated by Complementary Rack Cutters, Transactions of the Canadian Society for Mechanical Engineering 2017, 41, 281-291. https://doi.org/10.1139/tcsme-20171019.

[13] Chen, Y.; Lo, C. Contact stress and transmission errors under load of a modified curvilinear gear set based on finite element analysis, Proceedings of the Institution of Mechanical Engineers, Part C: Journal of Mechanical Engineering Science 2014, 229, 191-204. https://doi.org/10.1177/0954406214532907.

[14] Wu, Y.; Chen, K.; Tsay, C., et al. Contact Characteristics of Circular-Arc Curvilinear Tooth Gear Drives, Journal of Mechanical Design 2009, 131, 810031-810038. https://doi.org/10.1115/1.3151805.

[15] Zheng, F.; Han, X.; Lin, H., et al. Design and Manufacture of New Type of Non-Circular Cylindrical Gear Generated by Face-Milling Method, Mechanism and Machine Theory 2018, 122, 326-346. https://doi.org/10.1016/j.mechmachtheory.2018.01.007.

[16] Tseng, J.; Tsay, C. Mathematical Model and Surface Deviation of Cylindrical Gears with Curvilinear Shaped Teeth Cut by a Hob Cutter, Journal of Mechanical Design 2005, 127, 982-987. https://doi.org/10.1115/1.1876437.

[17] Tseng, J.; Tsay, C. Undercutting and Contact Characteristics of Cylindrical Gears with Curvilinear Shaped Teeth Generated by Hobbing. Journal of Mechanical Design 2006, 128, 634-643. https://doi.org/10.1115/1.2181605.

[18] Sun, Z.; Hou, L.; Wang, J., et al. Contact strength analysis of circular-arc-tooth-trace cylindrical gear. Journal of the Brazilian Society of Mechanical Sciences and Engineering 2016, 38, 999-1005. https://doi.org/10.1007/s40430-014-0272-6.

[19] Uzun, M. The investigation on manufacturing time of a new type concave-convex gear by a CNC milling machine. International Journal of Advanced Manufacturing Technology 2015, 77, 1275-1280. https://doi.org/10.1007/s00170-014-6541-9.

[20] Uzun, M.; Inan, A. Comparative Analysis of Curvilinear Gears With Produced by the New Production Method. Journal of Testing and Evaluation 2016, 44, 20140095. https://doi.org/10.1520/JTE20140095.

[21] Chang, Q.; Hou, L. Parallel Translating Mechanism Process-Oriented Mathematical Model and 3-D Model for Cylindrical Gears with Curvilinear Shaped Teeth. Jordan Journal of Mechanical and Industrial Engineering 2016, 10, 171-177.

[22] Zhang, Q.; Hou, L.; Tang, R., et al. Method of Processing and an Analysis of Meshing and Contact of Circular Arc Tooth Trace Cylindrical Gears. Transactions of FAMENA 2016, 40, 11-24. https://doi.org/10.21278/TOF.40402. 
[23] Zhang, X.; Xie, Y.; Tan, X. Design, Meshing Characteristics and Stress Analysis of Cylindrical Gears with Curvilinear Tooth Profile. Transactions of FAMENA 2016, 40, 27-44.

[24] Fuentes-Aznar, A.; Ruiz-Orzaez, R.; Gonzalez-Perez, I. Comparison of spur, helical and curvilinear gear drives by means of stress and tooth contact analyses. Meccanica 2017, 52, 1721-1738. https://doi.org/10.1007/s11012-016-0515-y.

Submitted: $\quad 05.3 .2020$

Accepted: $\quad 09.8 .2021$
Xuegang Zhang

School of Mechatronic Engineering, Southwest Petroleum University, Chengdu 610500, Sichuan, China;

School of Intelligent Manufacturing,

Panzhihua University, Panzhihua, 617000, Sichuan, China.

Zheng Liang*

School of Mechatronic Engineering,

Southwest Petroleum University, Chengdu 610500, Sichuan, China.

*Corresponding author:

liangz_2242@126.com 